\title{
Uma etnofotografia do Festival Cultural das Tribos Indígenas do Alto Rio Negro/ AM (Festribal)
}

\author{
Deise Lucy Oliveira Montardo \\ Universidade Federal do Amazonas/INCT Brasil Plural, Amazonas, Brasil \\ E-mail:deiselucy@gmail.com
}

\section{Hans Denis Schneider}

Universidade Federal de Santa Catarina/Fotografologia, Florianópolis, Brasil E-mail: hansdeniss@gmail.com 
Resumo

O Festival Cultural das Tribos Indígenas do Alto Rio Negro/AM (Festribal), na sua $16^{a}$ edição ocorrida em 201 l, é tratado aqui numa aproximação feita através de registros fotográficos e de uma observação parcial do evento. Esse Festival ocorre na cidade considerada uma das mais indígenas do país, São Gabriel da Cachoeira, e nele duas agremiações com nomes de etnias disputam o título de campeã. Nessas agremiações, os participantes são indígenas ou não indígenas. Já os convidados Yanomami vêm da sua localidade e se apresentam como eles mesmos. Discutimos brevemente a pertinência de usar a ideia de representação para tratar dessa situação.

Palavras-chave: São Gabriel da Cachoeira (AM). Festival folclórico. Povos indígenas. Alto Rio Negro.
Abstract

The Cultural Festival of Indigenous Peoples of the Upper Rio Negro/AM (Festribal), at its sixteenth edition in 2011, is treated here through a photographic approach which registers a partial observation of the event. This festival happens in the city considered to be one of the most indigenous city of the country of Brazil, São Gabriel da Cachoeira, and in it, two associations named after ethnic groups dispute the championship. The participants in the associations are indigenous or non-indigenous. Nonetheless, Yanomami guests come from their villages and present themselves as themselves. We briefly discuss the pertinence of using the idea of representation to treat this situation.

Keywords: São Gabriel da Cachoeira (AM). Folkloric festival. Indigenous Peoples. Upper Rio Negro. 


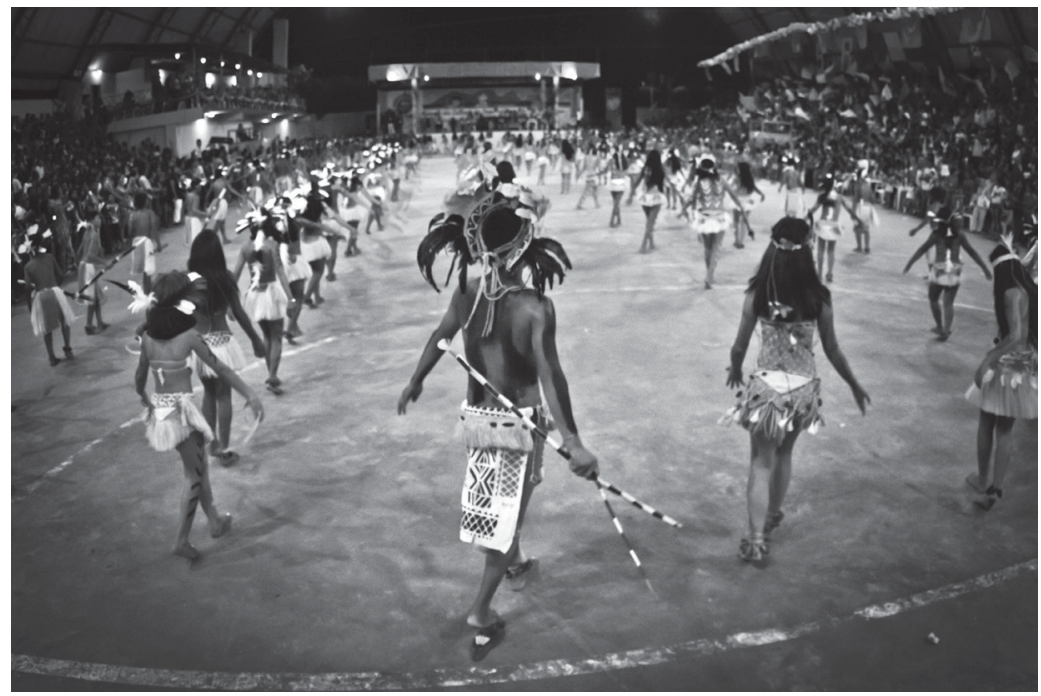

Figura 1 - XVI Festribal

Fonte: Hans Denis Schneider.

E m abril de 2011, os autores deste texto estavam em São Gabriel da Cachoeira, AM, para realizar a oficina de edição do projeto "Podáali: valorização da música Baniwa ${ }^{1 "} .^{2}$ Logo no dia em que chegamos, 16 de abril, nossos anfitriões nos contaram que estava sendo realizado o XVI Festival Cultural das Tribos Indígenas do Alto Rio Negro/AM (Festribal), cuja abertura seria naquela noite. Hans Denis Schneider, Moisés Baniwa e Paulinho Baniwa foram à Prefeitura e solicitaram entradas para fotografar e filmar o evento.

Baseados na observação parcial do evento e nas fotografias de Schneider é que esboçamos esta comunicação, sendo, portanto, uma primeira abordagem do tema.

Há uma tendência, na literatura da etnologia indígena, em recusar o uso da noção de representação para falar dos rituais indígenas. Optase por utilizar conceitos, tais como mimese, presentação, atualização 
dos mitos vivenciados em performance, entre outros. No entanto, há certos eventos performáticos em que a ideia de representação não só não seja incabível, como talvez seja preferível. Neste texto trataremos de um desses casos, o Festribal. Muito brevemente podemos afirmar que esse Festival foi criado na esteira dos vários que ocorrem no estado do Amazonas e que pipocaram num número grande de municípios, há cerca de 18 anos. Entre eles está um, mais antigo, mas que teve mudanças significativas nessa época, o Festival Folclórico de Parintins. Uma das características que marcam esses festivais é a polarização entre duas agremiações, que competem, como neste, entre o Boi Garantido e o Boi Caprichoso, objeto de significativas etnografias, como as de Cavalcanti (2000, 2002, 2006 e 2007) e Braga (2002), entre outros. Enquanto em Parintins, Fonte Boa, Nova Olinda e Benjamin Constant a rivalidade se dá entre agremiações dos boi-bumbás, em outros municípios as temáticas escolhidas para a disputa foram outros animais, como o peixe-boi em Novo Ayrão e Humaitá.

A possibilidade da criação de festivais que polarizem um aspecto importante da cidade permanece sempre no horizonte como incremento turístico e/ou de visibilidade. No Curso de Gestão de Projetos organizado para indígenas ${ }^{3}$ que aconteceu na UFAM entre 2009 e 2010 , durante um dos exercícios propostos, as representantes da Associação Indígena de Barcelos (Asiba) manifestaram a ideia de criar um festival da piaçava no município, no qual a rivalidade dar-se-ia entre a piaçava branca e a escura, dois espécimes desse vegetal que ainda hoje é objeto da exploração do trabalho escravo na região. ${ }^{4}$

Outro exemplo dessa perspectiva ocorreu no curso de Antropologia que a autora ministrou na licenciatura em Munduruku (UFAM), no município de Borba, em 2011. Durante uma das aulas, um grupo que estava falando sobre a Semana do Índio da Tribo Indígena Munduruku de Cacoal expôs a intenção do grupo de criar a competição entre dois grupos: um que representaria a dança dairu e outro a ware machuriri (jacaré boca fede), dois gêneros de dança mundurucu. A intenção deles é convidar jurados que tenham "conhecimento da cultura, como no Boi de Nova Olinda e Borba". Segundo eles, já está decidido e vai ser incentivado pelos professores. 
Como afirmamos anteriormente, o Festival de Parintins tem passado por várias transformações no processo de espetacularização, já analisado por Cavalcanti, entre outros. Em sua monografia, Batalha (2012) explora o surgimento de um item específico de avaliação no Festival de Parintins, o Ritual. Nesse item é enfatizada a citação do indígena, elemento que teve um incremento nos últimos anos. Nesse trabalho inicial ao tema, Batalha entrevistou os compositores do Boi, que afirmaram que até pouco tempo atrás citavam as etnias pela sonoridade dos nomes, sem muita preocupação com o conteúdo ou a historicidade ligados a elas. Nos últimos anos essa postura mudou e eles passaram a pesquisar e inclusive a visitar os grupos indígenas na busca de uma fidedignidade nas citações (Batalha, 2012).

Vamos agora, enfim, para o Festribal. São Gabriel da Cacheira é considerado o município mais indígena do Brasil. Seu território, de 109.185 $\mathrm{km}^{2}$, é, em boa parte, composto do Parque Nacional do Pico da Neblina, além das terras indígenas: Alto Rio Negro; Médio Rio Negro I, II e III; e Rio Tea. Sua população de 37.896 habitantes (IBGE, 2012) compreende 22 etnias falantes de várias línguas de três famílias linguísticas distintas: Aruak, Tukano e Maku. A sede do município é de um cosmopolitismo ímpar, tendo sido o primeiro do país a registrar a cooficialização de quatro línguas: português, baniwa, tukano e nengatu.

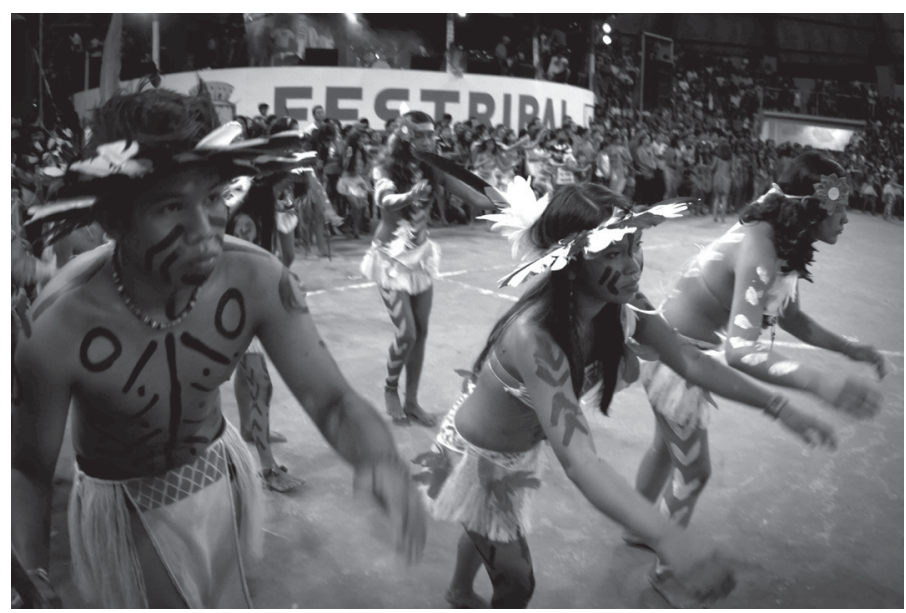

Figura 2 - Apresentação das agremiações

Fonte: Hans Denis Schneider. 
Assim, enquanto em Parintins a temática indígena foi incrementada nos últimos anos com a criação do Ritual, um item a mais no ato da apresentação das agremiações, em São Gabriel da Cachoeira, cidade eminentemente indígena, a apresentação se constitui do Ritual. Pode-se ouvir correntemente a opinião de que as músicas são iguais às do Boi de Parintins, toadas. Porém, no ano de 2011, em partes da apresentação, o que se ouviu foi o Ahãdeakü, gênero vocal feminino Tukano.

O Festribal foi realizado, nas suas primeiras edições, nos dias próximos ao Sete de Setembro, marcando as comemorações da Semana da Pátria. A partir do ano de 2010, foi transferido para a semana do dia 19 de abril, Dia do Índio. Essa mudança está relacionada, muito provavelmente, ao fato de a Prefeitura de São Gabriel estar sob o comando do prefeito e do vice-prefeito indígenas, Pedro Garcia, da etnia Tariano, e André Fernando, da etnia Baniwa.

No início eram três agremiações, Tukano, Baré e Baniwa. Após algumas edições, restaram duas agremiações, marcando o modelo de duas rivais.

Uma parte do Festival, promovida pelo Instituto Federal do Amazonas (IFAM), acontece na praia, durante o dia, e tem competições esportivas, como canoagem, arco e flecha, bem como uma competição de encenação de um ritual (Figura 2).

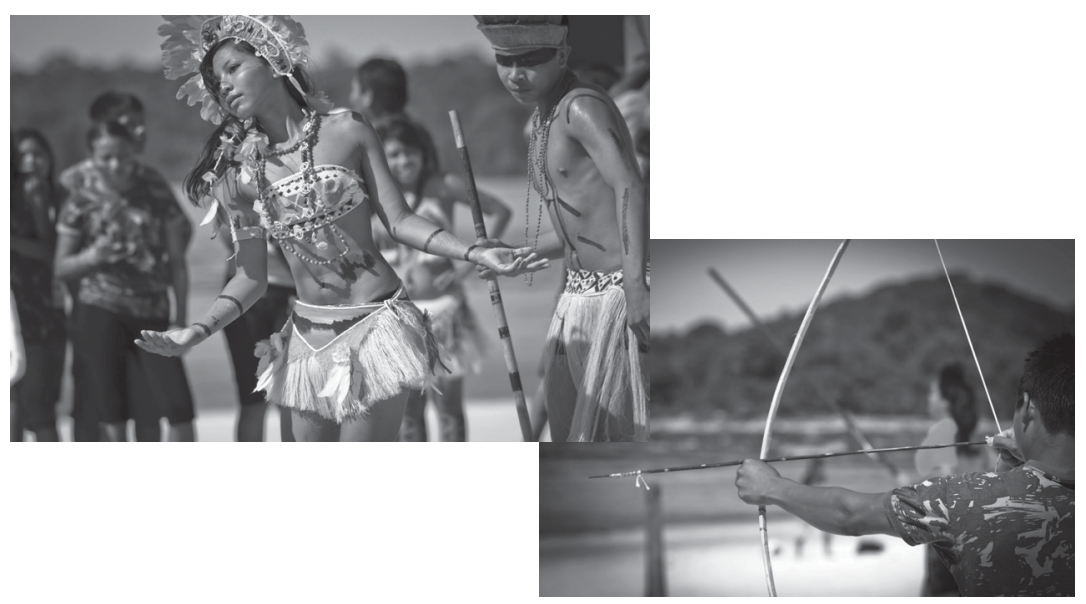

Figura 3 - Atividades do Festribal promovidas pelo IFAM, realizadas na praia Fonte: Hans Denis Schneider. 
A apresentação do ano de 2011 contou com uma abertura, marcada para as 20h, constituída pela apresentação da banda do Exército, que executou um repertório de músicas da bossa nova e o Hino Nacional. Depois disso, passou a acompanhar o Coral do Pastor Kim. Assim foi chamado o coral organizado pelo Pastor Cheoc Ki Kim, sul-coreano naturalizado brasileiro e vice-presidente do Instituto Bíblico do Alto Rio Negro (IBARN) (Figura 3).
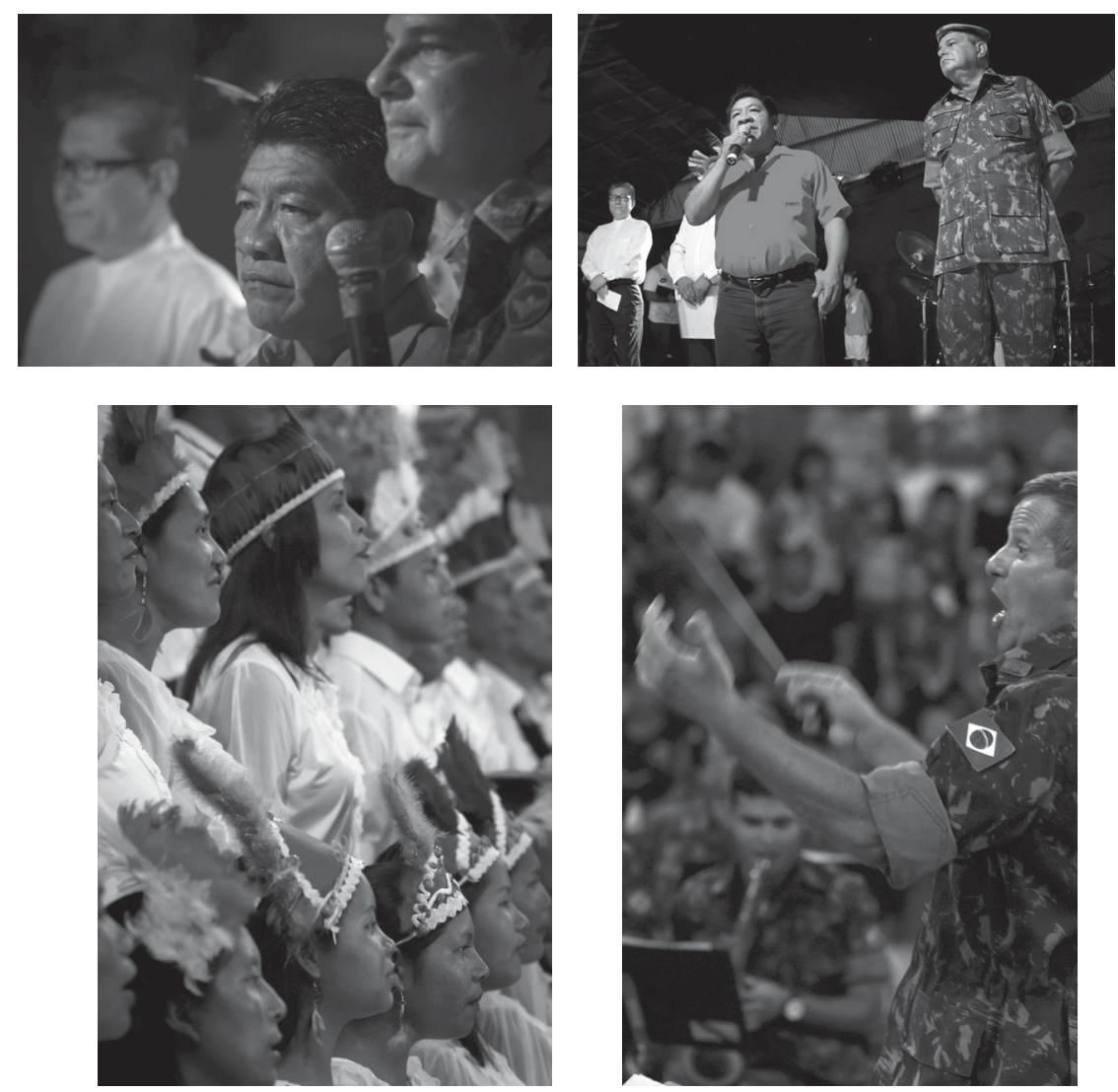

Figura 4 - Autoridades do município de São Grabriel da Cachoeira e Coral do Pastor Kim Fonte: Hans Denis Schneider.

Após esse momento, houve a entrada das autoridades, que se perfilaram para as fotos, o General do Exército José Luiz Jaborandy, o prefeito, Pedro Garcia, e o Pastor Kim (Figura 3). Chamou nossa 
atenção a autoridade religiosa do evento ser um pastor prebisteriano, ${ }^{5}$ e não um padre católico.

No dia seguinte, às 20h, ocorreu a apresentação das agremiações. Num primeiro momento tendemos a pensar que as agremiações reuniriam os indígenas de uma ou outra etnia, mas não. Vários dos nossos interlocutores indagados sobre o assunto disseram que a escolha é por simpatia. Nosso amigo Moisés Baniwa nos contou que já saiu em todas elas buscando a de sua preferência. No entanto, enquanto no Festival de Parintins os Comitês de Arte fazem uma pesquisa para compor o item do Ritual, em São Gabriel, um dos grupos, nesse ano a que assistimos, teve a participação e a encenação de cantos Tukano, com as próprias cantoras executando o gênero Ahãdeakü.

Em sua dissertação de mestrado, Piedade (1997) faz uma análise do Ahãdeakü, enfatizando seu caráter de improviso. No sistema rio-negrinho, é marcada a exogamia linguística, as mulheres sempre casam e vão viver com a família do marido, que é falante de outra língua que não a sua. Esse gênero musical feminino é cantado entre as performances masculinas, enquanto as mulheres, elas mesmas, servem o caxiri. Gabbay (2012), em etnografia mais recente feita com algumas mulheres indígenas na sede do município de São Gabriel, destaca que esse gênero, talvez pela sua característica de improviso, na cidade tem sido performatizado em outros contextos que não o do caxiri.

Recentemente, Magda Pucci e seu grupo Mawaca realizaram uma turnê na Amazônia na qual realizaram oficinas com grupos indígenas em cada cidade pelas quais passaram. Em Manaus a oficina foi com famílias Tukano. No show quem cantou foram mulheres e o gênero foi o Ahãdeakü, que encheu o Teatro Amazonas com sua sonoridade.

Outro destaque que queremos dar aqui são a entrada e a apresentação do grupo Yanomami no Festribal. Enquanto as associações culturais, como citamos, são integradas por moradores da cidade, indígenas e não indígenas, os Yanomami são convidados para se apresentarem como indígenas Yanomami. Sua entrada é envolta em sentimento de medo pelos outros participantes, como nos foi relatado por várias pessoas. "Os yanomami se apresentam com suas armas, com arcos e flechas armados, e se escapa uma?", ouvimos (Figura 4). 

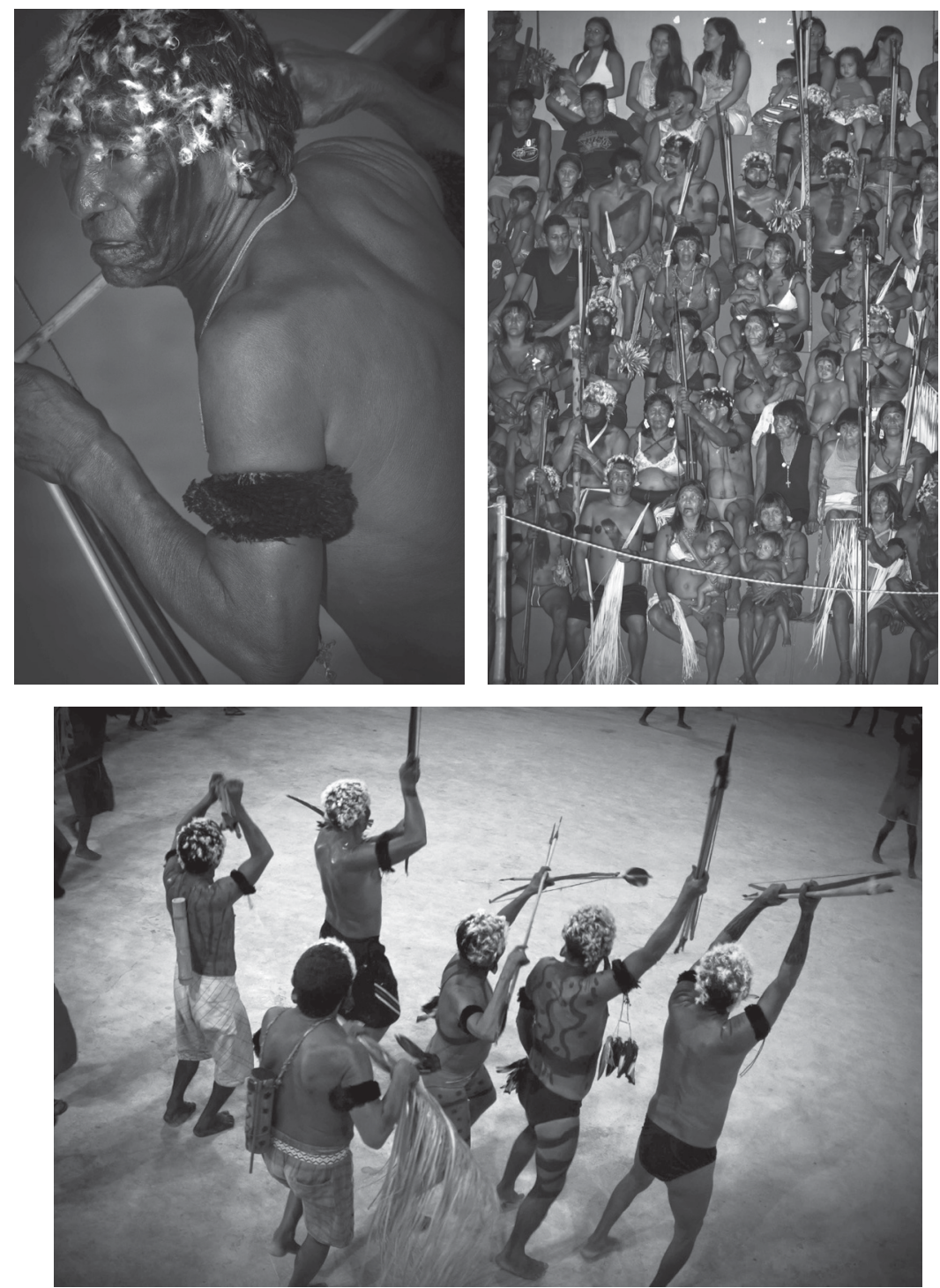

Figura 5 - Apresentação dos Yanomami no Festribal Fonte: Hans Denis Schneider.

Do lado de fora do Ginásio Arnaldo Coimbra, há muito movimento de barracas de comida, há um pavilhão de venda de artesanato, sendo uma das barracas nesse ano da Federação das Organizações Indígenas do Rio Negro (Foirn), que exibia vídeos antigos da missão salesiana. 
No pavilhão conhecido como Maloquinha, havia vários caxiris e nele se alternavam grupos tocando cariço e dançando forró.

Depois das apresentações houve shows de bandas e o movimento ficou intenso. Houve um rumor na cidade de que há muitas brigas, facadas, mortes... No entanto, nesse ano não presenciamos nada disso.

Como afirmamos inicialmente, este texto é uma entrada no tema e busca refletir sobre a performance do que é o indígena nos contextos dos festivais amazônicos, porém num município indígena. No texto do deputado estadual e professor da UFAM Eron Bezerra, bastante difundido na internet, é feita a seguinte afirmação:

A particularidade do Festribal, aquilo que lhe torna peculiar, não é apenas a magnitude do evento. Sua singularidade reside no fato de que o espetáculo não é uma encenação da cultura indígena e sim uma demonstração ao vivo dessa rica e desconhecida cultura, lamentavelmente desconhecida pela maioria do povo brasileiro (Eron Bezerra, 2010).

Nessa breve incursão ao Festribal, nossa impressão foi a de que sim, o que acontece é uma encenação no festival folclórico de São Gabriel da Cachoeira, com algumas citações da cultura indígena protagonizadas por indígenas e não indígenas. O sucesso desses festivais que são sucessivamente criados nos municípios nos coloca a seguinte questão: por que são tão bem-sucedidas essas iniciativas? Maria Laura Cavalcanti nos lembrou, em seu comentário durante o Colóquio, que os relatos dos viajantes dos primeiros séculos da colonização já traziam menções a grandes festas que aconteciam em algumas aldeias e que eram por esses chamadas de festivais. Isso vai acontecer com as festas de santos associadas ao calendário católico, nos séculos subsequentes. Ou seja, rituais intertribais não seriam novidade nessa região e isso talvez explique o sucesso que o Festribal tem nos dias atuais.

\section{Notas:}

1 Para mais detalhes sobre este projeto, ver Montardo (2011), Silva, Montardo e Silva (2012) e o vídeo "Podáali: um documentário da música Baniwa" (Baniwa $\theta$ Baniwa, 2011). 
2 Este projeto dos Baniwa residentes na comunidade Itacoatiara Mirim, em São Gabriel da Cachoeira, tem cerca de sete anos. Nesses anos eles captaram recursos, construíram a maloca na comunidade e realizaram o vídeo citado com vários recursos, entre eles, o patrocínio do Programa Petrobras Cultural, através do Edital de Patrimônio Imaterial. A nossa viagem para participar do trabalho contou também com o financiamento do INCT Brasil Plural.

3 Curso de Gestão de Projetos Indígenas do Corredor Central da Amazônia (MMA/ PDPI-UEA-UFAM-COIAB-CINEP).

4 As indígenas trabalhavam justamente num projeto de artesanato com piaçava que visava agregar valor ao produto, evitando a superexploração dos extrativistas quando vendiam o produto bruto.

5 Na página da internet do IBARN podemos ler a missão a que se propõe. O Instituto Bíblico do Alto Rio Negro foi levantado com o objetivo de evangelizar as 22 tribos que habitam a região do Rio Negro. Em abril de 1995 foi planejado e no dia 21 de março de 1997 começou seu funcionamento (GRAMIN, s/d).

\section{Referências}

BANIWA, Moisés; BANIWA, Paulinho (Dirs.). Podáali: um documentário da música Baniwa. São Gabriel da Cachoeira: ACICC/FOIRN, 2011.

BATALHA, Socorro. 2012. A presença indígena no Festival Folclórico de Parintins: um estudo sobre o processo de composição das toadas (1995-2010). Trabalho de Conclusão de Curso (Graduação em Ciências Sociais) Universidade Federal do Amazonas, Manaus, 2012.

BRAGA, Sérgio Ivan G. Os Boi-bumbás de Parintins. Rio de Janeiro: Funarte/ Ed. Universidade Federal do Amazonas, 2002.

CAVALCANTI, Maria Laura V. O Boi-bumbá de Parintins, Amazonas: breve história e etnografia da festa. História, Ciência e Saúde, Manguinhos, Rio de Janeiro: Fiocruz, v. VI, p. 1019-1046, 2000.

. Os sentidos no espetáculo. Revista de Antropologia, São Paulo: Ed. USP, v. 45, n. 1, p. 37-80, 2002.

. Tema e variantes do mito: sobre a morte e a ressurreição do boi. Mana: Estudos de Antropologia Social, v. 12, n. 1, p. 69-104, 2006.

. Brincando de Boi: antropologia dos Bois-bumbás de Parintins/ Amazonas. Ciência Hoje, SBPC, p. 18-25, ago. 2007.

ERON BEZERRA. Festribal: a festa dos índios. Disponível em: < http://www. eronbezerra.com.br/?p=214>. Acesso em: 10 nov. 2012.

GABBAY, Mariana. Lágrimas de boas-vindas: o repertório musical Ahãdeakü das comunidades indígenas de São Gabriel da Cachoeira no Alto Rio Negro, AM. Dissertação (Mestrado em Arte) - Programa de Pós-Graduação em Arte, Universidade Federal do Pará, Belém, 2012. 
GRAMIN. Disponível em: < http://www.gramin.org/por/mission/l1.html>. Acesso em: 6 abr. 2012.

IBGE. São Gabriel da Cachoeira: dados básicos. Disponível em: < http://www. ibge.gov.br/cidadesat/painel/painel.php?codmun=130380>. Acesso em: 10 dez. 2012.

MONTARDO, Deise Lucy O. A música indígena no mundo dos projetos etnografia do projeto "Podáali - valorização da música Baniwa". Trans 15, 2011.

PIEDADE, Acácio Tadeu de Camargo. 1997. Música yepamasa: por uma antropologia da música no Alto Rio Negro. Dissertação (Mestrado em Antropologia Social) - Universidade Federal de Santa Catarina, Florianópolis, 1997. Disponível em: <www.musa.ufsc.br>. Acesso em: 10 nov. 2012.

SILVA, Moisés Baniwa; MONTARDO, Deise Lucy; SILVA, Adeilson Lopes da. Projeto "Podáali: valorização da música Baniwa" e a Maloca Casa do Conhecimento: narrativa de um processo de transformação dos lugares do mundo. In: ANDRELLO, Geraldo (Org). Rotas de criação e transformação: narrativas de origem dos povos indígenas do Rio Negro, São Gabriel da Cachoeira. São Paulo: Instituto Socioambiental/FOIRN, 2012.

Recebido em 5/10/2012

Aceite em 30/10/2012 